\title{
GÊNERO E HISTÓRIA
}

\author{
Gender and History
}

Género e Historia

ALEJANDRA JOSIOWICZ ${ }^{I^{*}}$

DOI: http://dx.doi.org/10.1590/S2178-14942020000200001

'Editora convidada. Escola de Ciências Sociais da Fundação Getulio Vargas (CPDOC/FGV) - Rio de Janeiro (RJ), Brasil. *Pesquisadora do Instituto Interdisciplinario de Estudios de Género, da Facultad de Filosofía y Letras, da Universidade de Buenos Aires (IIEGE- FFyL- UBA), do Consejo Nacional de Investigaciones Científicas y Técnicas (CONICET) e pósdoutoranda no Programa de Pós-graduação em História, Política e Bens Culturais (PPHPBC) da Escola de Ciências Sociais da Fundação Getúlio Vargas (CPDOC/FGV) (alejandra.josiowicz@fgv.br).

(D) https://orcid.org/0000-0002-3525-1833 


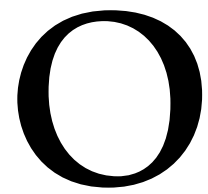

presente dossiê temático sobre gênero e história oferece uma cartografia do estado atual do campo dos estudos de gênero e do feminismo ibero-americano. Para tanto, adota uma estratégia multidisciplinar, incorporando as contribuiç̧ões da história cultural e social das mulheres e das relações de gênero, mas também da sociologia, da antropologia e dos estudos culturais em relação com o gênero, a sexualidade e o feminismo. Além disso, o dossiê tem uma perspectiva transnacional, incorporando pesquisadoras sobre gênero e feminismo baseadas em diversas regiões da Argentina, do Brasil, do Uruguai, dos Estados Unidos e da Espanha, que dão conta da particularidade dos estudos de gênero e da história das mulheres em cada país e região. Esse amplo panorama de pesquisas acadêmicas sobre o gênero e o feminismo na atualidade pretendeu incluir o trabalho tanto de pesquisadoras e professoras pioneiras e fundadoras do campo acadêmico dos estudos de gênero como daquelas gerações mais jovens. Repensar a história social e cultural do gênero e dos feminismos resulta central no momento presente, de profunda crise do capitalismo global, no qual o mundo se divide e se debate entre a mobilização e o caos dado pela falta de políticas públicas para enfrentar uma crise de saúde global sem precedentes. 0 feminismo, que já vinha enfrentando o retrocesso causado pelo ascenso em nível global de uma direita ultraconservadora, misógina e xenófoba, e suas políticas neoliberais e autoritárias, fazendo uso das ferramentas políticas marcadas pelo ativismo midiático, recrudesce sua luta e mobilização por direitos humanos fundamentais e por igualdade social, saúde, salário mínimo, serviços básicos, como abastecimento de água, informação, trabalho, educação, moradia e meio ambiente em um momento de emergência global.

0 crescimento exponencial dos estudos acadêmicos sobre o gênero e o feminismo nas últimas décadas tem apresentado desafios específicos no mundo ibero-americano, com a expansão dos programas de pós-graduação e disciplinas específicas da área. 0 primeiro deles é a articulação, já presente em décadas passadas, mas que tem adotado modalidades renovadas e uma interpenetração cada vez mais aprofundada, entre teoria e prática feminista, estudos acadêmicos e movimentos sociais, de modo tal que se, por um lado, as pesquisas têm-se dedicado a teorizar de modos inéditos as greves internacionalistas, as mobilizações dos feminismos indígenas, negros e decoloniais na América Latina e no Caribe, por outro os movimentos sociais têm utilizado as análises e teorizações dos feminismos latino-americanos, revelando assim a intensa reflexividade que articula o âmbito acadêmico e os movimentos sociais em nível local, regional e transnacional. Nesse sentido reflexivo deve ser lida a retomada do termo feminismo, eclipsado em anos anteriores pela categoria, mais lábil e fluida, de estu- 
dos de gênero e sexualidade, como símbolo da repolitização do campo e da nova centralidade que 0 ativismo ocupa no estudo acadêmico.

O segundo desafio é a superação de oposições estanques entre políticas de classe e políticas da identidade, de forma tal que revele os nexos entre modalidades do trabalho pago e não pago e categorias como raça, etnicidade, nacionalidade, gênero e sexualidade, como apontaram Nancy Fraser (2003) e Nancy Fraser et al. (2019). Não é possível desconstruir o essencialismo das políticas da identidade sem reconhecer que os diferentes eixos de subordinação se combinam de modos que afetam interesses de classe e categorias como raça, etnicidade, nacionalidade, gênero e sexualidade simultaneamente, gerando marginalização, exclusão e pobreza, simbólica e material.

0 terceiro desafio diz respeito ao modo pelo qual, na América Latina e no Caribe, os feminismos indígenas e negros, o feminismo decolonial, assim como os estudos da interseccionalidade, nascidos nos Estados Unidos, têm desconstruído a universalidade da noção de mulher e denunciado o compromisso histórico do feminismo, inclusive aquele feito na América Latina, com o imperialismo, o racismo e o etnocentrismo, articulando raça, etnia, classe, sexualidade e localização geopolítica. No Brasil, o pensamento feminista negro foi pioneiro em assinalar a natureza interconectada de raça, classe e gênero, recuperando a experiência das mulheres negras e indígenas e analisando práticas de opressão baseadas em hierarquias de gênero e raça (Carneiro, 2019). Sueli Carneiro (2019) ressaltou a especificidade de um feminismo negro latino-americano antirracista e a importância de uma perspectiva internacionalista que aponte para as relações entre globalização, neoliberalismo e feminização da pobreza, abrindo a possibilidade de alianças com outros países da América Latina e do Caribe. ${ }^{1}$ 0 pensamento feminista brasileiro também foi pioneiro do chamado feminismo decolonial, por meio da categoria de amefricanidade, de Lélia González (1988), a qual implica a experiência e a particularidade cultural de todos os países com heranças africana e indígena nas Américas (González, 1988). 0 projeto feminista decolonial vem apontando para a imbricação de dominação geopolítica, sexismo, racismo e capitalismo, pela articulação com os estudos pós-coloniais e decoloniais. Esses propõem um feminismo descentrado, excêntrico, desde as margens, capaz de pensar as mulheres do chamado Terceiro Mundo fora de uma visão etnocêntrica, exótica e reificada, assinalando os limites e as estratégias das políticas da identidade e apontando para a diversidade de experiências e formas de vida (Curiel Pichardo, 2009). Central nesse projeto é a revisão dos pressupostos epistemológicos da produção de conhecimento feminista que atribui um papel hierarquicamente superior às referências de teóricas e de conceitos europeus e norte-americanos, com a premissa de que o pensamento feminista elaborado nas regiões periféricas seria capaz de desconstruir a dependência intelectual da Eu- 
ropa e dos Estados Unidos (Curiel Pichardo, 2009). Voltando ao primeiro ponto, poderíamos dizer que as autoras recentes revelam a articulação não dicotômica entre a participação nos movimentos sociais, como espaços do ativismo, da voz e do reconhecimento, e a produção intelectual, dado que elas são fundadoras e produtoras de conhecimento e discurso, educadoras, pesquisadoras, professoras e estudantes.

Uma reflexão que deve ser feita de modo consciente e cada vez mais urgente nos estudos de gênero e feminismo na academia e nas diversas áreas da educação refere-se aos modos pelos quais, com o gênero como emblema, articulados com a ideologia da suposta meritocracia, sobrevivem práticas de exclusão e precarização de professoras, bolsistas, estagiárias, estudantes, em sua maioria mulheres de menor renda, gays, pessoas trans, mulheres e homens de cor, indígenas, sujeitos migrantes. 0 feminismo na academia não pode ser indiferente ante as práticas de exclusão e precarização do trabalho material e intelectual no interior das instituições educativas. Ao contrário, deve estar cada vez mais articulado com a luta pelo reconhecimento desses trabalhadores da educação, a valorização de suas produções intelectuais e do conhecimento por eles produzido, toda vez que ele quer contribuir para uma comunidade acadêmica mais democrática e justa.

0 dossiê é constituído de três partes principais. A primeira parte apresenta um simpósio ou entrevista coletiva feita a um grupo de figuras centrais, referências teóricas, vozes pioneiras e inovadoras nos estudos de gênero e feminismo na América Latina, provindas do Brasil, da Argentina, do Uruguai e dos Estados Unidos, na qual elas refletem sobre o presente e o futuro do campo.

A segunda parte conta com três colaborações especiais e traz três autoras brasileiras e uma argentina baseada nos Estados Unidos. São elas: Aparecida Fonseca Moraes, professora associada do Departamento de Sociologia e do Programa de Pós-Graduação em Sociologia e Antropologia da Universidade Federal do Rio de Janeiro (UFRJ), quem analisa as práticas discursivas da ativista Gabriela Leite no marco do processo de construção das prostitutas como sujeitos políticos no Brasil do século XX por meio da perspectiva da sociologia do indivíduo; Mariela Méndez, professora associada no Departamento de Latin American, Latino and Iberian Studies e de Women, Gender and Sexuality Studies da University of Richmond, cujo trabalho reflete sobre o novo ativismo feminista a partir de uma intervenção do movimento social Ni Una Menos na Argentina, utilizando a noção de performance coletiva. Por seu lado, Silvia Fávero Arend, professora do Programa de Pós-Graduação em História, da Universidade do Estado de Santa Catarina (UDESC) e Chirley Beatriz da Silva Vieira, doutoranda do Programa de Pós-Graduação em Educação da UDESC, escrevem um trabalho que analisa relações de classe e gênero nas ações de 
assistência social direcionadas às populações infanto-juvenis no Asilo de Órfãs São Vicente de Paulo, em Santa Catarina.

A terceira parte é composta de seis artigos selecionados entre um elevado número de artigos recebidos, após o processo de avaliação cega por pares. Trata-se de professoras, pesquisadoras, pós-doutorandas e doutorandas de universidades e instituições de pesquisa e educação da Argentina, da Espanha e do Brasil. 0 trabalho em coautoria de Gabriela de Lima Grecco (Departamento de Historia Contemporánea, Universidad Autónoma de Madrid) e Sara Martín Gutiérrez (Programa de Posdoctorado en Ciencias Humanas y Sociales de la Facultad de Filosofía y Letras - FFyL-CONICET) explora a censura literária no regime franquista, assim como as ações de resistência do coletivo de escritoras. Adriana Cristina Lopes Setemy (Programa de Pós-Graduação em História, Política e Bens Culturais — PPHPBC — da Escola de Ciências Sociais da Fundação Getulio Vargas - CPDOC/FGV) parte de uma perspectiva de gênero para refletir sobre a violência de Estado e a violação de direitos humanos durante a ditadura militar no Brasil. Marina Vieira de Carvalho (Departamento de História da Universidade Federal do Acre - UFAC) analisa a autoria feminina em periódicos pornô-eróticos do Rio de Janeiro do início do século XX como criação de uma sensibilidade erótica moderna. María Soledad González (doutoranda em História pela Universidad Nacional del Centro de la Provincia de Buenos Aires - UNCPBA/CONICET) faz uso de ferramentas dos estudos de gênero para analisar a trajetória de Victoria Ocampo como gerente artística e cultural que articula o público e o privado na Argentina da década de 1920. Eliza Teixeira Toledo (Casa de Oswaldo Cruz, Fundação Oswaldo Cruz - COC-Fiocruz) e Allister Teixeira Dias (Universidade Federal do Rio de Janeiro - UFRJ) analisam casos de "crimes passionais" com o objetivo de contribuir para a historicização da violência de gênero no Rio de Janeiro na década de 1930, apontando para a reificação e a naturalização da violência contra as mulheres. Finalmente, Verônica Toste Daflon (Universidade Federal Fluminense - UFF) e Luna Ribeiro Campos (Centro Federal de Educação Tecnológica Celso Suckow da Fonseca - CEFET-RJ) exploram as contribuiç̧ões de duas pioneiras da sociologia, Flora Tristan e Harriet Martineau. Vai o agradecimento, a propósito, às dezenas de pareceristas ad hoc que contribuíram voluntariamente com sua expertise para a composição final deste número.

\section{NOTA}

1 Com foco no feminismo negro estado-unidense, a teoria interseccional afirmou que as diferentes formas de dominação e subordinação de classe, raça, gênero, sexualidade e nação se inter-relacionam, construindo sistemas específicos de poder articulados, matrizes de dominação, estruturas distintivas com múltiplos níveis que funcionam de modos paralelos e 
interligados (Hill Collins, 1993; Andersen; Hill Collins, 2016). A proposta é transcender as barreiras que separam as diferentes formas de opressão, superando um pensamento dicotômico que hierarquiza os modos da opressão, e assinalar sua justaposição de acordo com padrões estruturais (Hill Collins, 1993; Andersen; Hill Collins, 2016).

\section{REFERÊNCIAS}

ANDERSEN, M. L.; HILL COLLINS, P. Race, Class \& Gender: An Anthology. 9. ed. Boston: Cengage Learning, 2016.

CARNEIRO, S. Enegrecer o feminismo. A situaçãa da mulher negra na América Latina a partir de uma perspectiva de gênero. In: ASHOKA EMPREENDIMENTOS SOCIAIS; TAKANO CIDADANIA (Org.). Racismos contemporâneos. Rio de Janeiro: Takano Editora, 2003. p. 49-58.

CURIEL PICHARDO, R. Y. O. Descolonizando el Feminismo: una perspectiva desde América Latina y el Caribe. In: COLOQUIO LATINOAMERICANO SOBRE PRAXIS Y PENSAMIENTO FEMINISTA, 1., 2009, Buenos Aires. Anais [...]. Buenos Aires, 2009.

GONZÁLEZ, L. A categoria político-cultural de Amefricanidade. Tempo Brasileiro, Rio de Janeiro, n. 92-93, p. 69-82, 1988.

HILL COLLINS, P. Toward a New Vision: Race, Class and Gender as Categories of Analysis and Connection. Race, Sex \& Class, v. 1, n. 1, p. 25-45, 1993.

FRASER, N. Social justice in the age of identity politics: Redistribution, recognition and participation. In: FRASER, N.; HONNETH, A. Redistribution or recognition: a political-philosophical exchange. Nova York: Verso, 2003.

FRASER, N.; ARRUZZA, C.; BHATTACHARYA, T. Feminism for the 99 Percent: a manifesto. Nova York: Verso, 2019. 